\title{
Enterovirus Inhibiting Activities of Two Lupane Triterpenoids and Anthraquinones from Senna Siamea Stem Bark Against Three Serotypes of Echovirus
}

\author{
Omonike 0. Ogbole ${ }^{1 *}$, Toluwanimi E. Akinleye ${ }^{1}$, Temitope 0. C. Faleye ${ }^{2,3}$, \\ Adekunle J. Adeniji ${ }^{3}$ \\ 1 University of Ibadan, Department of Pharmacognosy, Ibadan, Nigeria \\ 2 University of Ibadan, Department of Virology, College of Medicine, Ibadan, Nigeria \\ 3Ekiti State University, Department of Microbiology, Ado Ekiti, Nigeria
}

\begin{abstract}
Echovirus 7, 13 and 19 are part of the diseases-causing enteroviruses identified in Nigeria. Presently, no treatment modality is clinically available against these enteric viruses. Herein, we investigated the ability of two anthraquinones (physcion and chrysophanol) and two lupane triterpenoids (betulinic acid and lupeol), isolated from the stem bark of Senna siamea, to reduce the viral-induced cytopathic effect on rhabdomyosarcoma cells using MTT (3-[4,5-dimethylthiazol-2-yl]-2,5diphenyltetrazolium bromide) colorimetric method. Viral-induced CPE by E7 and E19 was inhibited in the presence of all tested compounds, E13 was resistant to all the compounds except betulinic acid. Physcion was the most active with $\mathrm{IC}_{50}$ of 0.42 and $0.33 \mu \mathrm{g} / \mathrm{mL}$ on E7 and E19, respectively. We concluded that these compounds from Senna siamea possess anti-enteroviral activities and betulinic acid may represent a potential therapeutic agent to control E7, E13, and E19 infections, especially due its ability to inhibit CPE caused by the impervious E13.
\end{abstract}

Keywords: Enteroviruses, cytopathic effect, Cassia siamea, anthraquinones, triterpenoids.

\footnotetext{
*Corresponding Author: Omonike Ogbole, e-mail: nikeoa@yahoo.com Omonike 0. Ogbole ORCID Number: 0000-0002-6487-9494 Toluwanimi E. Akinleye ORCID Number: 0000-0002-7202-8112

Temitope 0. C. Faleye ORCID Number: 0000-0001-7706-9493 Adekunle J. Adeniji ORCID Number: 0000-0002-0406-6707 (Received 18 April 2019, accepted 20 May 2019)
} 


\section{INTRODUCTION}

Echoviruses are members of Species B within the genus Enterovirus, family Picornaviridae, order Picornavirales. Within the genus are 15 Species (Enterovirus [EV] A - L and Rhinovirus A - C). The Polioviruses (PVs) are the best studied members of the genus and belong to EV-C. Enteroviruses are naked viruses with icosahedral symmetry and a diameter of $28-30 n M$. Within the virion is an approximately $7.5 \mathrm{~kb}$, positive-sense, single-stranded RNA genome. The genome encodes one large (>2,000 amino acid [Aa]) open reading frame

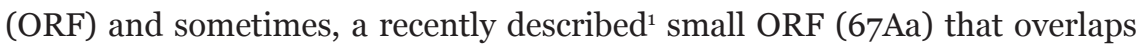
the large ORF and is involved in facilitating gut infection. The large ORF is translated into a polyprotein that is auto-catalytically cleaved into 11 proteins (four structural and seven non-structural proteins). The structural and nonstructural proteins are encoded in the 5' and 3'-ends of the ORF (and consequently, the genome), respectively.

Enteroviruses are associated with over a dozen clinical manifestation ${ }^{2}$, one of which is Acute flaccid Paralysis (AFP), the clinical presentation of poliomyelitis ${ }^{3}$. In Nigeria alone, over 10,000 suspected AFP cases are recorded annually ${ }^{4}$ This gives a sense of the clinical significance of EV infections globally. Many members of the genus have more than one clinical presentation ${ }^{2}$. Though vaccines exist for the PVs and EV-A71, neither vaccines nor chemotherapeutic agents exist for the control of other non-polio enteroviruses (NPEV) despite their association with different clinical presentations ${ }^{5-8}$. This therefore highlights the significance of antiviral drug development for EVs9

Natural products, either in form of pure compounds or standardized plant extracts, continue to provide rich and boundless source for the discovery and development of novel drug leads. The protective role of plant derived natural compounds against viral infection has been suggested by several studies ${ }^{10-13}$. Anthraquinones which are a class of naturally occurring and functionally diverse aromatic organic compounds, and are structurally related to or derived from anthracene have displayed well-known biological effects ${ }^{14}$. The antiviral activities of some anthraquinones such as physcion (a), chrysophanol (b) (figure 1), emodin, rhein, aloe-emodin, and chrysophanic acid against a range of viruses are well documented ${ }^{15-18}$. They inactivated enveloped virus or inhibit replication of un-enveloped virus such as EV-A71 in vitro ${ }^{14,19}$.

Lupane triterpenoids such as Betulinic acid (c) and Lupeol (d) (figure 1) have in the last two decades become of pharmacological interest when the anti-HIV and antineoplastic activities of betulinic acid was revealed ${ }^{20}$. The ability of betulinic acid to inhibit the replication of HIV and herpes simplex virus 1 (HSV-1) 
has been documented ${ }^{21,22}$. The anti-HIV protease activity and significant inhibition of HSV by lupeol has also been reported ${ }^{23}$.

Our previous work ${ }^{24}$ detailed the anti-poliovirus activities of two antraquinones (physcion and chrysophanol) $\left(\mathrm{IC}_{50}\right.$ values of 1.568 and $0.4571 \mu \mathrm{g} / \mathrm{mL}$ respectively), and two triterpenoids (lupeol and betulinic acid) ( $\mathrm{IC}_{50}=0.14 \mu \mathrm{g} /$ $\mathrm{mL}$ ). In continual pursuit of lead compounds that possess significant antiviral activity against EVs, this work therefore attempts to explore the anti-EV activities of two anthraquinones (physcion and chrysophanol) and two triterpenoids (lupeol and betulinic acid) isolated from Senna siamea against three (E7, E13, and E19) Echovirus types using cell-based antiviral assay.<smiles>COc1cc(O)c2c(c1)C(=O)c1cc(C)cc(O)c1C2=O</smiles>

(a) Physcion

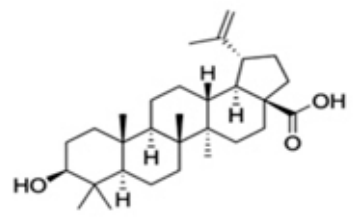

(c) Betulinic acid<smiles>Cc1cc(O)c2c(c1)C(=O)c1cccc(O)c1C2=O</smiles>

(b) Chrysophanol

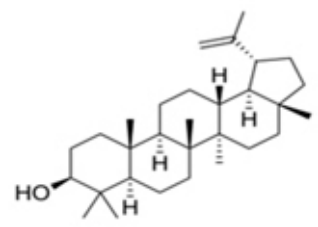

(d) Lupeol

Figure 1. Structure of selected anthraquinones ( $a$ and $b$ ) and Lupane triterpenoids ( $c$ and $d$ ).

\section{METHODOLOGY}

\section{Compounds isolation}

The details of isolation of the anthraquinones (physcion and chrysophanol) and the triterpenoids (lupeol and betulinic acid) from the stem bark of Senna siamea, and the spectroscopic methods employed for their structural elucidation have been previously described ${ }^{24}$.

\section{Viruses and Cells}

The three serotypes of Echovirus (E7, E13, and E19) used in this study were obtained from faeces of children with acute flaccid paralysis (AFP) in Nigeria$^{4}$. The isolates were provided by the Enterovirus Study Group (ESG), Department of Virology, University of Ibadan, Nigeria. Until use, all viruses were stored at $-80^{\circ} \mathrm{C}$. 
The antiviral and cytotoxic properties were measured in human rhabdomyosarcoma (RD) cells. The cell line was provided by the WHO National Polio Laboratory, University of Ibadan, Nigeria. The cells were grown in Eagle's minimum essential medium (MEM; Sigma-Aldrich) supplemented with 10\% fetal bovine serum (FBS), 100 units/mL of penicillin, $100 \mu \mathrm{g} / \mathrm{mL}$ of streptomycin, 2 mM L-glutamine, $0.07 \% \mathrm{NaHCO}_{3}, 1 \%$ non-essential amino acids and vitamin solution. The cells were incubated at $37{ }^{\circ} \mathrm{C}$ throughout the study period. The test medium used for cytotoxic assays and antiviral assays contained only $2 \%$ of fetal bovine serum (maintenance medium).

\section{Tissue culture infective dose (TCID)}

Virus-induced cytopathic effect (CPE) in RD cell culture was used in determining virus titres, which were expressed as 50\% tissue culture infective dose $\left(\mathrm{TCID}_{50}\right)$ per $\mathrm{mL}$ using Sperman-Karber's method. Microtitre plates were used for this assay and the assay was done in Triplicates. Precisely, $100 \mu \mathrm{L}$ RD cell suspension $\left(1 \times 10^{6}\right.$ cells $\left./ \mathrm{mL}\right)$ was seeded into 96-well microtitre plates and incubated for $24 \mathrm{~h}$ to form monolayer. Ten-fold serial dilutions of the virus stock was made and $100 \mu \mathrm{L}$ of each dilution was inoculated into the wells. The cell control wells contained $100 \mu \mathrm{L}$ RD cell suspension alongside10o $\mu \mathrm{L}$ of medium without any virus. The microtitre plate was sealed and incubated at 37 ${ }^{\circ} \mathrm{C}$. Daily CPE scoring was done till the cells in the control wells started dying. The TCID $_{50}$ values was determined using Spearman-Karber's method.

\section{Cytotoxicity assay}

The maximum non-toxic concentration (MNTC) and the 50\% cytotoxic concentration $\left(\mathrm{CC}_{50}\right)$ for each compound was obtained using MTT cytotoxicity assay. Each compound was pre-solubilized in DMSO to give $1 \mathrm{mg} / \mathrm{mL}$ stock solution. Ten-fold serial dilutions (1000 to $0.01 \mu \mathrm{g} / \mathrm{mL}$ ) of the compounds were made using the maintenance medium. Confluent monolayers of RD cells in each well of a 96-well microplate was treated with the different concentrations of each compound. Plates were incubated at $37^{\circ} \mathrm{C}$ for $72 \mathrm{~h}$. Subsequently, plates were observed under the inverted microscope for cytopathic effect (CPE). The old medium was then removed and $25 \mu \mathrm{L}$ of MTT solution $(2 \mathrm{mg} / \mathrm{mL}$ ) was added to each well and incubated for $2 \mathrm{~h}$ at $37^{\circ} \mathrm{C}$. Thereafter, the MTT solution was removed from the wells and DMSO $(75 \mu \mathrm{L})$ was added. Spectrophotometric (Multiscan 347, MTX lab) measurement of the plates was made at $490 \mathrm{~nm}$ to obtain optical density values, and the $50 \%$ cytotoxic concentration $\left(\mathrm{CC}_{50}\right)$ was calculated. The experiment was conducted in triplicate. 


\section{Antiviral activity assay}

The antiviral effect of the compounds against E7, E13, and E19 was determined pre-infection (prophylactic) using a cell culture-based assay that measures viral cytopathic effect inhibition. The method as previously described ${ }^{25}$ was modified and used in this assay. Briefly, RD cells were seeded in a 96-well microplate and incubated for $24 \mathrm{~h}$ to grow to confluence. After the incubation period, two-fold serial dilutions, obtained from the MNTC of each compound were added in triplicate into all the wells with the exception of the negative control wells that contained only RD cells and the virus control that contained virus without any compound. After about an hour, $50 \mu \mathrm{L}$ of $100 \mathrm{TCID}_{50}$ virus suspension were added to all the wells except the negative control wells. The plates were incubated at $37^{\circ} \mathrm{C}$ in the incubator for $72 \mathrm{~h}$ after which the cell viability was measured using the MTT assay as earlier described. The 50\% inhibitory concentration $\left(\mathrm{IC}_{50}\right.$ ) was estimated from the obtained optical density. No drug control was used in this study, since there are no antiviral drugs approved for the treatment of EV infections.

\section{Data analysis}

The $\mathrm{CC}_{50}$ (50\% cytotoxic concentration) and the $\mathrm{IC}_{50}$ (50\% inhibitory concentration) for the compounds were calculated from concentration-effect-curves after linear regression analysis using GraphPad Prism5 and Microsoft Excel. The selectivity index (SI), defined as $\mathrm{CC}_{50}$ over $\mathrm{IC}_{50}$, for each active compound were also determined.

\section{RESULTS AND DISCUSSION}

\section{MNTC and $\mathrm{CC}_{50}$ of compounds}

Lupeol exacted the most cytotoxic effect on the RD cells in culture by having the lowest maximum non-toxic concentration (MNTC) of $0.1 \mu \mathrm{g} / \mathrm{mL}$ and $\mathrm{CC}_{50}$ value of $0.51 \mu \mathrm{g} / \mathrm{mL}$. Other lupane triterpenoid (Betulinic acid) and anthraquinones (Physcion and Chrysophanol) all had moderate cytotoxic effect on the $\mathrm{RD}$ cells with equal MNTC of $10 \mu \mathrm{g} / \mathrm{mL}$ and $\mathrm{CC}_{50}$ values of 49.50, 39.12, and $14.91 \mu \mathrm{g} / \mathrm{mL}$, respectively. Results are presented in Table 1.

\section{Antiviral activities of compounds}

E13 was resistant to the CPE inhibitory effect of all the compounds tested except Betulinic acid. Physcion had the highest antiviral activity on the E7 and E19 serotypes with $\mathrm{IC}_{50}$ values of 0.42 and $0.33 \mu \mathrm{g} / \mathrm{mL}$, respectively. Physcion also displayed good selectivity, with sufficiently high selective indices of 93.14 and 118.55, respectively on E7 and E19. Triterpenoid, Lupeol displayed low an- 
tiviral activity against the three serotypes, and particularly no selectivity with SI values less than 1 for the three serotypes. However, Betulinic acid which is also a triterpenoid had the highest antiviral activity on $\mathrm{E} 19\left(\mathrm{IC}_{50}=0.31 \mu \mathrm{g} / \mathrm{mL}\right)$ and moderate antiviral activity on $\mathrm{E}_{7}$ and $\mathrm{E} 13\left(\mathrm{IC}_{50}=4.46\right.$ and $4.43 \mu \mathrm{g} / \mathrm{mL}$, respectively). It also displayed good selectivity $(>10)$ for the three serotypes. The results are presented in Table 1.

Nigerian ethnobotany has reported Senna siamea Lam (Fabaceae) as a component of remedies used against viral infections in the country ${ }^{26}$. Furthermore, the antiviral activities of various compounds (such as chromones, triterpenoids, and anthraquinones) isolated from the stem of this plant against HIV-1, poliovirus-1 (PV-1) and tobacco mosaic virus (TMV) has been reported ${ }^{24,27}$. In this study, we confirm these findings and further expand the breadth of EV types against which these compounds have documented antiviral activity.

Physcion which was isolated as yellow crystals from the hexane soluble fraction of Senna siamea stem bark displayed the highest inhibition and good selective indices against E7 and E19 (Table 1). However, a similar anthraquinone (chrysophanol, Figure 1), which had been previously documented ${ }^{24,28}$ to have anti-poliovirus activity, only had moderate inhibitory effect with low selective index on these Echovirus types.

Betulinic acid was the next in the antiviral activity against the three Echovirus types investigated in this study (Table 1). It is important to note that E19 was significantly more inhibited by betulinic acid in tissue culture than E7 and 13 . The pronounced inhibitory effect of betulinic acid on another serotype of echovirus (E6) has been reported ${ }^{20}$. Therefore, the findings of this study appear to support that of Tolstikova and others (2006).

While betulinic acid showed significant anti-Echovirus activity in this study, it showed weak anti-poliovirus activity in our previous study ${ }^{24}$. As with the anthraquinones, a similar triterpenoid (Lupeol, Figure 1), which had been previously documented ${ }^{24,} 28$ to strongly inhibit poliovirus-induced CPE, herein exhibited the least antiviral activity with poor selectivity $(\mathrm{SI}=<1)$ against $\mathrm{E} 7$ and E19 and none against E13 (Table 1).

Considering, the Echoviruses investigated in this study (Table 1) and the PVs investigated in our previous study ${ }^{24,28}$ belong to Species EV-B and EV-C, respectively, the contrasting antiviral activity of the two anthraquinones and triterpenoids appear to be in consonance with the different EV species. This suggests that peculiar biological properties of EVs that follow species demarcations might be responsible for their sensitivity to selected anthraquinones and triterpenoids. 
It did not escape our notice that within the Echoviruses (which are all EV-B members) described in this study, differences also exist in their sensitivity to the anthraquinones and triterpenoids. It should be noted that only two of the Echoviruses analysed in this study were sensitive to the anti-Echovirus activity of the anthraquinone Physcion. On the other hand, all three viruses were sensitive to the anti-Echovirus activity of the triterpenoid, Betulinic acid. Furthermore, though the actual values as measured in the assays differ (Table 1), the degree of anti-Echovirus activity of Physcion seems to be similar for E7 and E19 while that for Betulinic acid seems similar for E7 and E13. Put together, these patterns suggest that the mechanism of action of anti-Echovirus activity of Physcion and Betulinic acid might differ.

Table 1. Anti-Echovirus activity of compounds

\begin{tabular}{|l|l|l|l|l|l|l|l|l|}
\hline \multirow{2}{*}{ Compound } & $\begin{array}{l}\text { MNTC } \\
(\mu \mathrm{g} / \mathrm{mL})\end{array}$ & $\mathbf{C C}_{50}(\mu \mathrm{g} / \mathrm{mL})$ & \multicolumn{2}{|l|}{ IC $_{50}(\mu \mathrm{g} / \mathrm{mL})$} & \multicolumn{3}{l|}{ SI } \\
\cline { 2 - 10 } & & & E7 & E13 & E19 & E7 & E13 & E19 \\
\hline Physcion & 10 & 39.12 & 0.42 & NA & 0.33 & 93.14 & NA & 118.55 \\
\hline Chrysophanol & 10 & 14.91 & 5.42 & NA & 5.75 & 2.75 & NA & 2.59 \\
\hline Betulinic Acid & 10 & 49.50 & 4.46 & 4.43 & 0.31 & 11.10 & 11.17 & 159.68 \\
\hline Lupeol & 0.1 & 0.51 & 7.10 & NA & 6.43 & $<1$ & NA & $<1$ \\
\hline
\end{tabular}

NA- Not active; SI- selective index; $\mathrm{IC}_{50}-50 \%$ inhibitory concentration; $\mathrm{CC}_{50}-50 \%$ cytotoxic concentration

Considering the design of the assay for antiviral activity, only prophylactic and not therapeutic activity was assayed. Hence, it is either the compounds prevented attachment or entry of the virus into the permissive and susceptible cell line used for this assay, or they induced an antiviral state by targeting a replication stage that is downstream of entry. The fact that E7, E13 and E19 have been documented to all use the same cell surface receptor (Decay-Accelerating Factor [DAF]) for entry into susceptible cells ${ }^{2,29,30}$, the differing assay results for the three EVs suggest inhibition might not have occurred at entry. However, if their footprints ${ }^{31}$ on the receptor differ or if alternate cell surface receptors $^{32,33}$ exist for one or more of the Echoviruses analysed in this study, then it is possible that the observed phenotype might be due to attachment or entry inhibition. 
Physcion has been documented to interact with pathways involved in post -attachment or -entry stages of EV replication like the autophagy pathway ${ }^{34,35}$. Therefore, considering the reasons mentioned above we are of the opinion that the inhibition of Echovirus (7, 13 and 19) replication observed in this study occurred at a post -attachment or -entry stage. Hence, effort is ongoing to further dissect the molecular basis of these activities in an effort to understand the biological basis of observed variations both within and among EV Species.

In summary, we have reported the antiviral activity of two anthraquinones (physcion and chrysophanol) and two triterpenoids (betulinic acid and lupeol) isolated from the stem bark of Senna siamea against three serotypes of Echovirus (E7, E13, and E19), with physcion exhibiting the most potent antiviral activity.

National Research Council recommended that an ideal poliovirus drug must be one that is also active on other enteroviruses ${ }^{36}$. Therefore, the anthraquinones (physcion and chrysophanol) which were previously reported active on poliovirus could be considered for development into poliovirus therapeutic agents. However, particularly fascinating is the fact that we have found it difficult to find compounds that inhibit E13 replication ${ }^{37}$, Hence the observation that E13 is susceptible to inhibition by Betulinic acid is remarkable and therefore also deserves further investigation. 


\section{REFERENCES}

1. Lulla, V.; Dinan, A. M.; Hosmillo, M.; Chaudhry, Y.; Sherry, L.; Irigoyen, N.; Nayak, K. M.; Stonehouse, N. J.; Zilbauer, M.; Goodfellow, I. An Upstream Protein-Coding Region in Enteroviruses Modulates Virus Infection in Gut Epithelial Cells. Nature microbiology 2019, 4, 280 .

2. Royston, L.; Tapparel, C. Rhinoviruses and Respiratory Enteroviruses: Not as Simple as Abc. Viruses 2016, 8, 16.

3. WHO, Polio Laboratory Manual. 4th Edition ed. 2004, Geneva, Switzerland: World Health Organisation.

4. Faleye, T.; Adewumi, M.; Japhet, M.; David, O.; Oluyege, A.; Adeniji, J.; Famurewa, O. Non-Polio Enteroviruses in Faeces of Children Diagnosed with Acute Flaccid Paralysis in Nigeria. Virol. J. 2017, 14, 175.

5. Park, K. S.; Choi, Y. J.; Park, J. S. Enterovirus Infection in Korean Children and AntiEnteroviral Potential Candidate Agents. Korean J. Pediatr. 2012, 55, 359-366.

6. Kang, H.; Kim, C.; Kim, D. E.; Song, J. H.; Choi, M.; Choi, K.; Kang, M.; Lee, K.; Kim, H. S.; Shin, J. S.; Kim, J.; Han, S. B.; Lee, M. Y.; Lee, S. U.; Lee, C. K.; Kim, M.; Ko, H. J.; van Kuppeveld, F. J.; Cho, S. Synergistic Antiviral Activity of Gemcitabine and Ribavirin against Enteroviruses. Antiviral. Res. 2015, 124, 1-10.

7. Zuo, J.; Kye, S.; Quinn, K. K.; Cooper, P.; Damoiseaux, R.; Krogstad, P. Discovery of Structurally Diverse Small-Molecule Compounds with Broad Antiviral Activity against Enteroviruses. Antimicrob. Agents Chemother. 2015, 6o, 1615-26.

8. Nikonov, O. S.; Chernykh, E. S.; Garber, M. B.; Nikonova, E. Y. Enteroviruses: Classification, Diseases They Cause, and Approaches to Development of Antiviral Drugs. Biochem. (Mosc) 2017, 82, 1615-1631.

9. Abzug, M. J. The Enteroviruses: Problems in Need of Treatments. J. Infect. 2014, 68, S108-S114.

10. Zarubaev, V. V.; Anfimov, P. M.; Shtro, A. A.; Garshinina, A. V.; Meleshkina, I. A.; Karpinskaia, L. A.; Kozeletskaia, K. N. Kiselev, O. I. [Development of Novel Drugs against Influenza Virus Based on Synthetic and Natural Compounds]. Vopr. Virusol. 2012, 57, 30-6.

11. Numakawa, T. Possible Protective Action of Neurotrophic Factors and Natural Compounds against Common Neurodegenerative Diseases. Neural. Regen. Res. 2014, 9, 1506-8.

12. Mohd Sairazi, N. S.; Sirajudeen, K. N.; Asari, M. A.; Muzaimi, M.; Mummedy, S. Sulaiman, S. A. Kainic Acid-Induced Excitotoxicity Experimental Model: Protective Merits of Natural Products and Plant Extracts. Evid. Based Complement. Alternat. Med. 2015, 2015, 1-15.

13. Jardim, A. C. G.; Shimizu, J. F.; Rahal, P.; Harris, M. Plant-Derived Antivirals against Hepatitis C Virus Infection. Virol. J. 2018, 15, 34.

14. Dave, H.; Ledwani, L. A Review on Anthraquinones Isolated from Cassia Species and Their Applications. Indian J. Nat. Prod. Resour. 2012, 3, 291-319.

15. Abd-Alla, H. I.; Abu-Gabal, N. S.; Hassan, A. Z.; El-Safty, M. M.; Shalaby, N. M. Antiviral Activity of Aloe Hijazensis against Some Haemagglutinating Viruses Infection and Its Phytoconstituents. Arch. Pharm. Res. 2012, 35, 1347-1354.

16. Al-Mohizea, A. M.; Al-Omar, M. A.; Abdalla, M. M.; Amr, A. G. 5alpha-Reductase Inhibitors, Antiviral and Anti-Tumor Activities of Some Steroidal Cyanopyridinone Derivatives. Int. J. Biol. Macromol. 2012, 50, 171-9. 
17. Alam, Z.; Al-Mahdi, Z.; Zhu, Y.; McKee, Z.; Parris, D. S.; Parikh, H. I.; Kellogg, G. E.; Kuchta, A.; McVoy, M. A. Anti-Cytomegalovirus Activity of the Anthraquinone Atanyl Blue Prl. Antiviral. Res. 2015, 114, 86-95.

18. Fouillaud, M.; Venkatachalam, M.; Girard-Valenciennes, E.; Caro, Y.; Dufosse, L. Anthraquinones and Derivatives from Marine-Derived Fungi: Structural Diversity and Selected Biological Activities. Mar. Drugs, 2016, 14, 64.

19. Li, S. W.; Yang, T. C.; Lai, C. C.; Huang, S. H.; Liao, J. M.; Wan, L.; Lin, Y. J.; Lin, C. W. Antiviral Activity of Aloe-Emodin against Influenza a Virus Via Galectin-3 up-Regulation. Eur. J. Pharm. 2014, 738, 125-132.

20. Tolstikova, T.; Sorokina, I.; Tolstikov, G.; Tolstikov, A.; Flekhter, O. Biological Activity and Pharmacological Prospects of Lupane Terpenoids: I. Natural Lupane Derivatives. Russ. J. Bioorgan. Chem. 2006, 32, 37-49.

21. Ryu, S. Y.; Lee, C. K.; Lee, C. O.; Kim, H. S.; Zee, O. P. Antiviral Triterpenes Fromprunella Vulgaris. Arch. Pharmacal Res. 1992, 15, 242-245.

22. Moghaddam, M. G.; Ahmad, F. B. H. and Samzadeh-Kermani, A. Biological Activity of Betulinic Acid: A Review. Pharmacol. Pharm. 2012, 3, 119.

23. Wei, Y.; Ma, C. M.; Chen, D. Y.; Hattori, M. Anti-Hiv-1 Protease Triterpenoids from Stauntonia Obovatifoliola Hayata Subsp. Intermedia. Phytochem. 2008, 69, 1875-1879.

24. Ogbole, O.; Adeniji, J.; Ajaiyeoba, E.; Kamdem, R.; Choudhary, M. Anthraquinones and Triterpenoids from Senna Siamea (Fabaceae) Lam Inhibit Poliovirus Activity. Afr. J. Microbiol. Res. 2014, 8, 2955-2963.

25. Lin, Y. J.; Chang, Y. C.; Hsiao, N. W.; Hsieh, J. L.; Wang, C. Y.; Kung, S. H.; Tsai, F. J.; Lan, Y. C.; Lin, C. W. Fisetin and Rutin as 3c Protease Inhibitors of Enterovirus A71. J. Virol. Methods 2012, 182, 93-98.

26. Ajaiyeoba, E.; Ogbole, O.; Ogundipe, O. Ethnobotanical Survey of Plants Used in the Traditional Management of Viral Infections in Ogun State of Nigeria. Eur. J. Sci. Res. 2oo6, 13, 64-73.

27. Hu, Q. F.; Zhou, B.; Gao, X. M.; Yang, L. Y.; Shu, L. D.; Shen, Y.; Li, G. P.; Che, C. T.; Yang, G. Y. Antiviral Chromones from the Stem of Cassia Siamea. J. Nat. Prod. 2012, 75, 1909-1914.

28. Semple, S. J.; Pyke, S. M.; Reynolds, G. D.; Flower, R. L. In Vitro Antiviral Activity of the Anthraquinone Chrysophanic Acid against Poliovirus. Antiviral Res. 2001, 49, 169-178.

29. Powell, R. M.; Ward, T.; Goodfellow, I.; Almond, J. W.; Evans, D. J. Mapping the Binding Domains on Decay Accelerating Factor (Daf) for Haemagglutinating Enteroviruses: Implications for the Evolution of a Daf-Binding Phenotype. J. Gen. Virol. 1999, 8o, 3145-3152.

30. Baggen, J.; Thibaut, H.; Strating, J. R.; van Kuppeveld, F. J. The Life Cycle of Non-Polio Enteroviruses and How to Target It. Nat. Rev. Microbiol. 2018, 16, 368-381.

31. Yoder, J. D.; Cifuente, J. O.; Pan, J.; Bergelson, J. M.; Hafenstein, S. The Crystal Structure of a Coxsackievirus B3-Rd Variant and a Refined 9-Angstrom Cryo-Electron Microscopy Reconstruction of the Virus Complexed with Decay-Accelerating Factor (Daf) Provide a New Footprint of Daf on the Virus Surface. J. Virol. 2012, 86, 12571-12581.

32. Pinkert, S.; Röger, C.; Kurreck, J.; Bergelson, J. M.; Fechner, H. The Coxsackievirus and Adenovirus Receptor: Glycosylation and the Extracellular D2 Domain Are Not Required for Coxsackievirus B3 Infection. J. Virol. 2016, 90, 5601-5610.

33. Novoselov, A. V.; Rezaykin, A. V.; Sergeev, A. G.; Fadeyev, F. A.; Grigoryeva, J. V.; Sokolo- 
va, Z. I. A Single Amino Acid Substitution Controls Daf-Dependent Phenotype of Echovirus 11 in Rhabdomyosarcoma Cells. Vir. Res. 2012, 166, 87-96.

34. Pang, M. J.; Yang, Z.; Zhang, X. L.; Liu, Z. F.; Fan, J.; Zhang, H. Y. Physcion, a Naturally Occurring Anthraquinone Derivative, Induces Apoptosis and Autophagy in Human Nasopharyngeal Carcinoma. Acta Pharm. Sin. 2016, 37, 1623.

35. Mohamud, Y.; Luo, H. The Intertwined Life Cycles of Enterovirus and Autophagy. Virul. 2018, [Epub ahead of print], 1-11.

36. National Research Council. 2006. Exploring the Role of Antiviral Drugs in the Eradication of Polio: Workshop Report. Washington, DC: The National Academies Press.

37. Ogbole, O. O.; Akinleye, T. E.; Segun, P. A.; Faleye, T. C.; Adeniji, A. J. In Vitro Antiviral Activity of Twenty-Seven Medicinal Plant Extracts from Southwest Nigeria against Three Serotypes of Echoviruses. Virol. J. 2018, 15, 110. 